\title{
Effectiveness of habitat management in the recovery of low-density populations of wild rabbit
}

\author{
Sérgio Godinho - Frederico Mestre - Joaquim P. Ferreira • \\ Rui Machado • Pedro Santos
}

Received: 17 February 2013 /Revised: 2 May 2013 / Accepted: 9 May 2013 /Published online: 7 June 2013

(C) Springer-Verlag Berlin Heidelberg 2013

\begin{abstract}
Understanding the relationship between spatial patterns of landscape attributes and population presence and abundance is essential for understanding population processes as well as supporting management and conservation strategies. This study evaluates the influence of three factors: environment, habitat management, and season on the presence and abundance of the wild rabbit (Oryctolagus cuniculus), an important prey species for Mediterranean endangered predator species. To address this issue, we estimated wild rabbit presence and abundance by latrine counting in transects located in 45 plots within a $250 \times 250 \mathrm{~m}$ grid from June 2007 until June 2009 in a 1,200 ha hunting area in southern Portugal. We then
\end{abstract}

Communicated by: C. Gortázar

S. Godinho $(\bowtie) \cdot$ R. Machado $\cdot$ P. Santos

Instituto de Ciências Agrárias e Ambientais Mediterrânicas (ICAAM),

Mediterranean Ecosystems and Landscapes Research Group

(MEL), Departamento de Paisagem, Ambiente e Ordenamento,

Universidade de Évora, Ap. 94,

7002-554 Évora, Portugal

e-mail: godinho.sergio@gmail.com

R. Machado

e-mail: rdpm@uevora.pt

P. Santos

e-mail: aps@uevora.pt

F. Mestre

Centro de Investigação em Biodiversidade e Recursos Genéticos (CIBIO-UE), Departamento de Biologia, Universidade de Évora, 7002-554 Évora, Portugal

F. Mestre

e-mail: mestre.frederico@gmail.com

J. P. Ferreira

CESAM and Department of Biology, University of Aveiro,

Campus Universitário de Santiago,

3810-193 Aveiro, Portugal

e-mail: joaquimpedro.ferreira@gmail.com analyzed how wild rabbit presence and abundance correlate with the aforementioned factors. Our results showed that the main variable influencing wild rabbit presence and abundance was the distance to the artificial warrens. North and northeast slope directions were negatively related to wild rabbit presence. Conversely, rabbit presence was positively correlated with short distances to ecotone, artificial warrens, and spring. Regarding rabbit abundance, in addition to artificial warrens, soft soils, bushes, and season also had a positive effect. We found that environmental variables, management practices, and season each affect wild rabbit presence and abundance differently at a home range scale in low-density population. Thus, our major recommendations are reducing the distance to artificial warrens and ecotone, ideally to less than $100 \mathrm{~m}$, and promoting habitat quality improvement on slopes with plenty of sun exposure.

Keywords Environmental factors $\cdot$ Habitat management · Oryctolagus cuniculus $\cdot$ Portugal $\cdot$ Season

\section{Introduction}

The wild rabbit (Oryctolagus cuniculus) is a key prey in the Iberian Peninsula (Delibes-Mateos et al. 2007) as an item in the diet of more than 40 predator species (Delibes and Hiraldo 1981; Delibes-Mateos et al. 2008a). Some of these predators, such as the critical endangered Iberian lynx ( Lynx pardinus) and the vulnerable Spanish imperial eagle (Aquila adalberti), which are both endemic to the Iberian Peninsula, depend on high rabbit densities to breed (reviewed by Delibes-Mateos et al. 2008a).

Over the past five decades, the wild rabbit has declined significantly across the Iberian Peninsula for two main reasons: disease (myxomatosis and rabbit hemorrhagic disease; Villafuerte et al. 1995; Fernández 2005) and habitat degradation and/or fragmentation from land use changes (Moreno 
and Villafuerte 1995; Moreno et al. 1996; Delibes-Mateos et al. 2010). This population decline has induced deep negative consequences in the Mediterranean predator community (Moreno et al. 2004; Delibes-Mateos et al. 2007). To address this accentuated wild rabbit decline, both in Spain and Portugal, recovery strategies based on predator control, vaccination programs, and restocking and habitat management have been developed for hunting and conservations purposes (Calvete et al. 1997). Habitat management is often used because it is relatively easy to implement and it is effective in increasing rabbit abundance on the local scale (Moreno and Villafuerte 1995; Villafuerte et al. 1997; Angulo and Villafuerte 2003; Moreno et al. 2004; Catalán et al. 2008; Delibes-Mateos et al. 2008b; Ferreira and Alves 2009). In fact, although habitat management can sometimes be coupled to restocking, usually it promotes the reinforcement of local rabbit populations avoiding some negative aspects linked to restocking, such as high mortality of restocked rabbits (Calvete et al. 1997) and mixing of genetic lineages (Delibes-Mateos et al. 2008c).

In Portugal, a decree law of 2008 established a national action plan to conserve Iberian lynx (legislation no. 12697/2008) and more recently, the project LIFE $^{+}$ IBERLINCE was approved for Portugal and Spain. The ultimate target of both efforts is to reintroduce the species in its historic territories. The success of these projects will depend largely on proper knowledge of the wild rabbit's spatial bio-ecology, habitat, and population management. Research on the ecology of the wild rabbit and the influence of habitat management techniques on its abundance have been conducted in Portugal (Ferreira and Alves 2009) and Spain (Moreno and Villafuerte 1995; Palomares et al. 1996; Catalán et al. 2008). Indeed, $18 \%$ of wild rabbit literature in the Iberian Peninsula focuses on management topic, which aims at investigating the effectiveness of specific rabbit conservation/management actions (Ferreira 2012).

Despite the existence of numerous studies, recent work has shown interesting results that contribute positively to improving the wild rabbit habitat management strategy. Calvete et al. (2004) showed that wild rabbit abundance increased only when the edge between alternate cereal crops was less than $50 \mathrm{~m}$ from the ecotone between crops and natural vegetation. On the other hand, Barrio et al. (2009) investigating a low-density wild rabbit population suggested that habitat variables are only secondary factors, and that the location and use of warrens is influenced mainly by spatial factors, such as proximity to other nearby warrens. In another study, Barrio et al. (2011) examined high-density populations on an agricultural landscape and concluded that the main variable explaining natural warren occurrence was the distance to the nearest neighboring warren. In the case of a low-density population, however, to our knowledge, no research has evaluated the simultaneous influence of environmental variables, habitat management techniques, and seasonal effects on wild rabbit presence and abundance.

The goal of the present study was to assess the role of different types of variables on the presence and abundance of wild rabbit in low-density populations. In order to increase these populations, several measures of habitat management were implemented. According to previous considerations of wild rabbit bio-ecology and recovery programs, we hypothesize that habitat management techniques should play a major role in the presence and abundance of wild rabbit in the Algarve mountain range. We examined wild rabbit presence and abundance in a region that is particularly important for the potential recovery of the Iberian lynx because it is part of the historical distribution range of the species (Sarmento et al. 2009). A home-range scale approach was used to best accomplish the purpose of seeking information that would enhance wild rabbit management at the nucleus level.

\section{Methods}

\section{Study area}

The present study was conducted in a hunting area (in which rabbit hunting was prohibited) of the Caldeirão mountain range in southern Portugal (Fig. 1). The area, which is characterized by a Mediterranean mesothermic temperate climate with hot and dry summers and mild winters, belongs to the Mediterranean Ibero-Atlantic province (RivasMartínez and Lloidi 1999).

With 1,224 ha, the area is part of the Nature 2000 Network, with 986 ha belonging to the Caldeirão Nature 2000 site and 238 ha to the Barrocal Nature 2000 site. The altitude ranges from 160 to $430 \mathrm{~m}$, and the main soils are Leptosols $(78.1 \%$ of the area) and Cambisols $(8.7 \%)$. Leptosols are thin soils over rock, which makes it difficult for wild rabbits to dig warrens. In contrast, Cambisols are deeper and softer soils that are more suitable for warren digging. Cork oak (Quercus suber) forest is the major cover, occupying about $41.6 \%$ of the area; bushes (35.3\%), agricultural fields (orchards and crops, $20.6 \%$ ), and Pinus sp. $(2.3 \%)$ occupy the remainder of the area.

\section{Wild rabbit survey}

Latrine counts have been used widely as an indirect and easy-to-implement method to estimate rabbit abundance (Virgós et al. 2003; Calvete et al. 2006; Beja et al. 2007, 2008; Sarmento et al. 2012). However, recent investigations have shown some limitations in latrine counts to estimate wild rabbit abundance, mainly in regional wild rabbit monitoring programs (Fernandez-de-Simon et al. 2011). Despite 

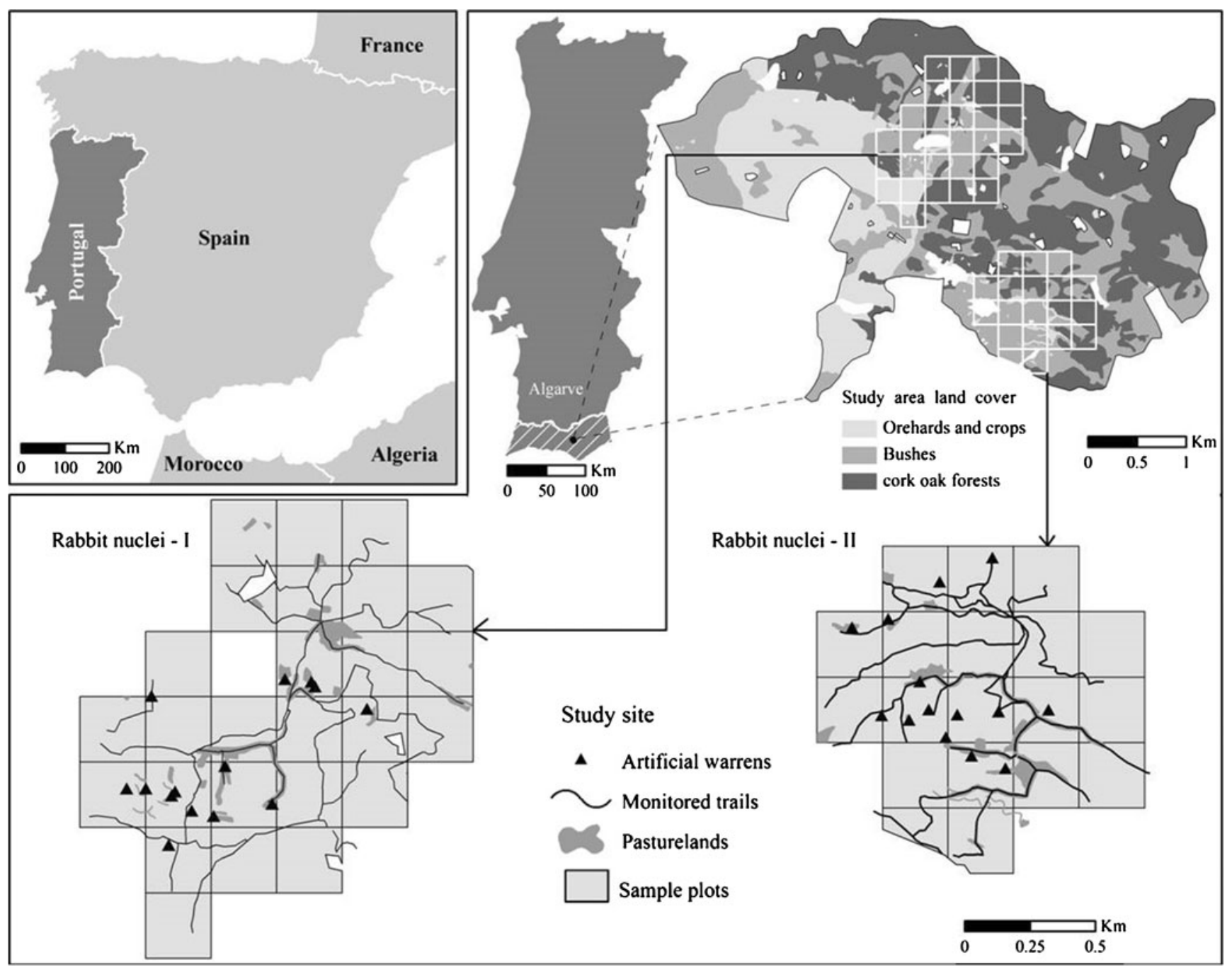

Fig. 1 Geographic location of the study area and study site, land cover of study area, management interventions, monitored trails, and sample plots

these limitations, we used latrine counts because the present study was developed on a local scale, and it has been argued that latrine counts may result locally in reproducible variations in densities (Fernandez-de-Simon et al. 2011). In addition, this indirect method was used because observing individuals in the study area was very difficult due to the dense vegetation cover and rough topography.

Because we do not know the size of the rabbit home range in our region, we divided the study area into a $250 \times$ $250 \mathrm{~m}$ grid so that each sample plot of 6.25 ha encompassed the size of most wild rabbit home ranges known in the Iberian Peninsula (Monteiro 1994; Lombardi et al. 2007). According to the initial survey conducted in March 2006, we verified very low wild rabbit abundance, finding only eight independent nuclei in the entire hunting area. To improve two of the nuclei, we promoted the habitat management techniques mentioned above in 35 sample plots of the total 45 plots used for monitoring. Therefore, our study site consisted of these selected 45 sample plots, which encompassed the adjacent areas of the two nuclei.

To assess wild rabbit recovery in these two nuclei, we estimated wild rabbit presence and abundance (dependent variables) through latrine counts in each sample plot. Latrine was defined as any fecal accumulation having at least 50 pellets over a surface of $30 \mathrm{~cm}$ in diameter (Iborra and Lumaret 1997). The latrine counts occurred across all existing trails in the 45 sample plots by thoroughly searching for the presence of latrines within a $15.0 \mathrm{~m}$ wide strip on each side of the trail. Once a month from July 2007 to June 2009 (with the exception of March 2008 and February 2009), one observer surveyed a total of $18.45 \mathrm{~km}$ of trails in the 45 sample plots. During the monitoring period, the observer surveyed always the same trails. The kilometric abundance index (KAI), which represents the total latrines counted per kilometer sampled, was calculated for each sample plot and used as a proxy variable of wild rabbit abundance. 
Environmental factors and habitat management techniques

Environmental factors influencing wild rabbit presence and abundance were divided into three sets of explanatory variables: soils, topography, and land cover. The two existing soil types in the sample plots (Leptosols and Cambisols) were extracted from a soils map of Portugal (1:50,000; SROA 1961). For topographic variables, we considered the slope direction and the distance to temporary streams. The slope direction was calculated based on a 5-m resolution digital elevation model. To assess slope direction, we used the following classes: north, northeast, east, southeast, south, southwest, west, and northwest. To quantify the influence of temporary streams on rabbit abundance and presence, we selected three distance classes $(<50,50-100$, and $>150 \mathrm{~m})$. For both topographic variables, we determined the proportion of area occupied by each class within each sample plot. For a detailed description of this spatial analysis approach, see Appendix 1. Finally, land cover maps were obtained based on the photointerpretation of digital orthophotos from 2006 $(1: 10,000)$, which were validated with field checks carried out in 2007, 2008, and 2009. Quantities of the area's soil types, topographic variables, and land cover classes within each sample plot were obtained using the Geographic Information System software ArcGis 9.3 (ESRI 2008. ArcGIS Desktop: Release 9.3. Redlands, CA, USA: Environmental Systems Research Institute).

To improve the habitat quality for wild rabbit, the following actions were implemented from 2006 to 2009: managing scrubland, creating pasturelands, and building artificial warrens. To promote a more heterogeneous land cover mosaic, several open areas were created inside large scrubland patches (e.g., Ferreira and Alves 2009). Pasture patches were partially renewed and expanded during the studied period. The most used species were Secale cereal, Triticosecale Wittmack, Avena spp., Lupinus luteus, and Lathyrus cicera. Some specific prearranged seed mixes were applied in several open areas to enrich soil fertility and retard bush recovery. At the same time, both scrubland management and pasture implementation, contributed to the increase in ecotone length between shelter patches and open areas or crops. Artificial warrens were built using wood pallets and vegetal remains from the surroundings and then covered by soil. Most were located near feeding and shelter areas (Fernández-Olalla et al. 2010). Warrens were considered occupied when signs of rabbit activity, such as fecal pellets, footprints, and scratches were found near the entrances without cobwebs or plants (Palomares 2003; Barrio et al. 2009). To evaluate the effect of distance to habitat elements (artificial warrens and ecotone zone (interface between scrubland and open areas/crop patches)), we used the same approach described above (see Appendix 1).
Data analysis

Prior to data analysis, wild rabbit abundance data were transformed with $\log (x+1)$ to approach normality and reduce the influence of extreme values (Legendre and Legendre 1998). The angular transformation ( $\operatorname{arcsine} \sqrt{ } x$ ) was used to normalize the proportional independent variable data and obtain homogeneity of variances (Legendre and Legendre 1998). Due to the high colinearity observed among independent variables, we used principal component analysis (PCA) to reduce the 23 variables to a small number of independent components. Using the approach Calvete et al. (2004) developed to facilitate interpretation, several PCAs were performed within groups of related independent variables (temporary streams distances-PCA, artificial warrens distances-PCA, ecotone distances-PCA, slope direction-PCA, and landscape attributes-PCA; Table 1). We used a varimax-normalized rotation in the principal components with eigenvalues $>1$ to obtain simpler and more interpretable ecological gradients (Legendre and Legendre 1998). We considered as determinant variables for each principal component only those with component loading values $>0.5$. PCA results (independent components) were used as quantitative explanatory variables to obtain predictive models for wild rabbit presence and abundance (dependent variables).

Preliminary screening and reduction of independent variables (PCA results) were undertaken with univariate generalized linear mixed models (GLMM) for wild rabbit presence and univariate linear mixed-effects models (LMM) for wild rabbit abundance. For posterior analysis, we retained only the independent variables with univariate significance $<0.10$. To assess the effects of environmental factors, habitat management techniques, and season of the year (season) on wild rabbit, we performed GLMM statistical analysis with a binomial distribution for wild rabbit occurrence probability (using presence/absence data) and LMMs with Gaussian distribution for the wild rabbit abundance model (using relative abundance expressed by $\log (\mathrm{KAI}+1)$ ). We investigated the presence of spatial autocorrelation in the dependent variables based on Moran's $I$ coefficients analysis with the spline.correlog function of the R 2.10.1 software package (R Development Core Team 2009) ncf (Bjornstad 2009). Given the observed spatial autocorrelation in the dependent variables, the sample plots were treated as random effects, with all other independent variables treated as fixed effects (Zuur et al. 2009). Using sample plots as random effects, the spatial autocorrelation of the residuals was removed. All mixed models were fitted using the lmer function (lme4 package) for wild rabbit presence (Bates and Maechler 2010) and the lme function (nlme package) for wild rabbit abundance (Pinheiro et al. 2007).

For the two dependent variables, models with all possible combinations of the remaining variables (after univariate 
Table 1 Principal component analysis for independent variables used in the models. Values in italics indicate component loadings of $>|0.50|$

Distance index of temporary streams (TSD)

$>150$

$50-100$

$<50$

Distance index of artificial warrens (WDI)

$$
\begin{aligned}
& >150 \\
& 50-100
\end{aligned}
$$$$
<50
$$

Ecotone distance index (EDI)

$$
\begin{aligned}
& >150 \\
& 50-100 \\
& <50
\end{aligned}
$$

Slope direction $(\mathrm{SD})$

\section{North}

Northeast

East

Southeast

South

Southwest

West

Northwest

Eigenvalues

Explained variance

Landscape attributes (soils and land cover) (LA)

Leptosols
Cambisols
Dense bushes
Pinus pinaster and Pinus pinea L. with bushes
Q. suber without bushes
Crops

Eigenvalues
Distance index of temporary streams-PCA (unrotated solution)

$-0.91$

0.97

0.94

Eigenvalues $\quad 2.67 \quad$ Explained variance

$88.91 \%$

Distance index of artificial warrens-PCA (unrotated solution)

$-0.92$

0.98

0.94

$\begin{array}{llll}\text { Eigenvalues } & 2.71 & \text { Explained variance } & 90.30 \%\end{array}$

Ecotone distance index-PCA (unrotated solution)

$-0.96$

0.90

0.85

\begin{tabular}{|c|c|c|}
\hline PC1-LA & PC2-LA & PC3-LA \\
\hline 0.71 & -0.37 & 0.10 \\
\hline-0.12 & 0.81 & 0.30 \\
\hline 0.72 & 0.12 & -0.28 \\
\hline 0.19 & 0.77 & -0.22 \\
\hline-0.75 & -0.28 & -0.31 \\
\hline 0.04 & 0.02 & 0.94 \\
\hline 1.70 & 1.45 & 1.15 \\
\hline & & Explained variance \\
\hline
\end{tabular}

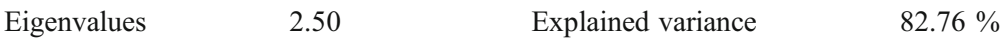

Slope direction-PCA (varimax rotation)

$\begin{array}{llll}\text { PC1-SD } & \text { PC2-SD } & \text { PC3-SD } & \text { PC4-SD } \\ 0.31 & 0.27 & -0.18 & 0.85 \\ -0.43 & -0.30 & 0.00 & 0.81 \\ -0.78 & 0.26 & -0.40 & 0.03 \\ -0.16 & 0.74 & -0.07 & -0.02 \\ 0.93 & -0.08 & -0.06 & 0.01 \\ 0.43 & -0.54 & 0.64 & 0.03 \\ 0.01 & 0.24 & 0.91 & -0.16 \\ -0.03 & 0.91 & 0.22 & 0.04 \\ 2.60 & 1.77 & 1.37 & 1.05 \\ & & & 85.16 \%\end{array}$

Landscape attributes-PCA (varimax rotation) screening) were developed and compared with Akaike's information criterion corrected for small samples $\left(\mathrm{AIC}_{\mathrm{c}}\right.$; Burnham and Anderson 2002). Because the small sample size, we considered to have substantial support as candidate models all models with $\triangle \mathrm{AIC}_{\mathrm{c}}<4$ (Burnham and Anderson 2002). We calculated the Akaike weights $\left(w_{i}\right)$ as the model selection criteria (Burnham and Anderson 2002), where the highest $w_{i}$ represent the best model for biological interpretations. Finally, the relative importance of each independent variable was performed using the framework Burnham and Anderson (2002) described. This measure of relative importance was calculated as the sum of the Akaike weights $\left(\sum w_{i}\right)$ over all of the best models $\left(\Delta \mathrm{AIC}_{\mathrm{c}}<4\right)$ in which the independent variable of interest appears. 


\section{Results}

Environmental factors and habitat management techniques

Distance index of temporary streams (TSD) explained $88.9 \%$ of the variance (Table 1). For the distance index of artificial warrens (WDI), the PCA results explained $90.3 \%$ of the variance (Table 1). The ecotone distance index (EDI) explained $83.8 \%$ of the existing variability (Table 1 ). All of these three distances indexes showed a strong positive relationship between distance classes less than $100 \mathrm{~m}$ and a negative relation with distances greater than $150 \mathrm{~m}$ (Table 1). The PCA performed for slope direction (SD) variables retained as significant four PCs that together explained $85.2 \%$ of the overall variance contained in the original variables (Table 1). The PC1-SD component describes the gradient between the east and south slope directions. The PC2-SD shows an opposition between slopes with southwest direction and the southeast and northwest directions. Finally, PC3-SD and PC4-SD describes the southwest and west and the north and northeast slope directions, respectively (Table 1). The PCA conducted for the six landscape attributes extracted three components with eigenvalues of $>1$, which together accounted for $72.0 \%$ of the variance in the original data (Table 1). The PC1-LA revealed a gradient from areas with Leptosols and dense bushes to areas completely covered by $Q$. suber without bush. PC2LA component describes areas where shelter attributes, mainly bushes and moderate soft soil (Cambisols), dominated. The third PC (PC3-LA) showed a positive correlation with feeding areas (crop patches; Table 1).

From 2006 to 2009, 28 artificial warrens were built in the study site (Table 2). Over the study period, the artificial warren occupancy by wild rabbit showed a gradual increase, reaching $64.3 \%$ in 2009 (Table 2). Concerning feeding areas, a total of 14.0 ha of pasturelands were created and distributed by 49 sown patches with an average size of 0.5 ha (Table 2). Due to the pastureland and scrubland management actions, we favored a more diverse mosaic landscape in which pasturelands and open areas were intercepted by shrubs, accumulating a total of $11.8 \mathrm{~km}$ of ecotone in 2009 (Table 2).

Wild rabbit survey

A total of 2,445 wild rabbit latrines were recorded along $405.9 \mathrm{~km}$ of trails surveyed during the monitoring period (22 months). Rabbits were absent in 18 of the 45 sample plots surveyed (zero latrines $/ \mathrm{km}$ ). In sample plots with rabbit presence, the mean KAI was 6.7 latrines $\mathrm{km}^{-1}$ in summer 2007 and 24.5 latrines $\mathrm{km}^{-1}$ in spring/early summer 2009 (March to June; Fig. 2). In global terms, the evolution of the relative abundance of rabbit shows a gradual population increase in line with improved habitat quality (Fig. 3).

After univariate analyses, we retained six variables for the multivariate modeling procedure for rabbit presence and seven variables for rabbit abundance (Table 3). Regarding the wild rabbit presence, we selected a single model that best fits the data from 14 candidate adjusted models (Table 4). Based on Akaike weights, the model with the additive effect of WDI, EDI, PC4-SD, and SE (model 1) was the best supported. This model has the highest Akaike weight value, presenting the best compromise between maximal fit and minimal number of explanatory variables (Table $4, w_{i}=0.23$ ). The selected model highlights the significant positive effect of artificial warren and ecotone distance less than $100 \mathrm{~m}$ and season. The model shows, however, that north and northeast slope directions (PC4SD) have a negative effect on wild rabbit occurrence (Table 4). As for the proxy variable of wild rabbit abundance, the triple additive model WDI + PC2-LA+SE has the highest Akaike weight value (Table $4, w_{i}=0.42$ ), suggesting that distances less than $100 \mathrm{~m}$ from artificial warrens, soft soils (Cambisols), bushes, and season were the main factors affecting wild rabbit abundance. Despite the relatively low $w_{i}$ values of these two selected models $\left(w_{i}=0.23\right.$ and $w_{i}=$ 0.42), some independent variables showed high relative

Table 2 Annual habitat management measures carried out in the surrounding areas of the two monitored wild rabbit nuclei

\begin{tabular}{|c|c|c|c|c|c|c|c|c|}
\hline \multirow[b]{2}{*}{ Year } & \multicolumn{4}{|c|}{ Artificial warrens } & \multicolumn{4}{|c|}{ Promoted crop areas } \\
\hline & $\begin{array}{l}\text { Total } \\
\text { number }\end{array}$ & $\begin{array}{l}\text { Occupied } \\
(\%)\end{array}$ & $\begin{array}{l}\text { Total } \\
\text { (ha) }\end{array}$ & $\begin{array}{l}\text { Renewed } \\
\text { (ha) }\end{array}$ & $\begin{array}{l}\text { Expanded } \\
\text { (ha) }\end{array}$ & $\begin{array}{l}\text { Accumulated } \\
\text { (ha) }\end{array}$ & $\begin{array}{l}\text { Crop } \\
\text { patches }\end{array}$ & $\begin{array}{l}\text { Ecotone length } \\
(\mathrm{km})^{\mathrm{b}}\end{array}$ \\
\hline $2006^{\mathrm{a}}$ & 13 & 7.7 & 6.3 & - & - & 6.3 & 6 & 6.5 \\
\hline 2007 & 25 & 48.0 & 7.0 & 1.4 & 5.5 & 11.8 & 29 & 10.3 \\
\hline 2008 & 28 & 60.7 & 8.8 & 6.6 & 2.1 & 14.0 & 49 & 11.8 \\
\hline 2009 & 28 & 64.3 & 0.0 & 0.0 & 0.0 & 14.0 & 49 & 11.8 \\
\hline
\end{tabular}

${ }^{a}$ Habitat management measures implemented before our sampling period.

${ }^{\mathrm{b}}$ Ecotone between crops/bushes and open areas/bushes (promoted by bush management). 
Fig. 2 Monthly patterns of wild rabbit abundance (latrines per kilometer) in study site during the monitored period

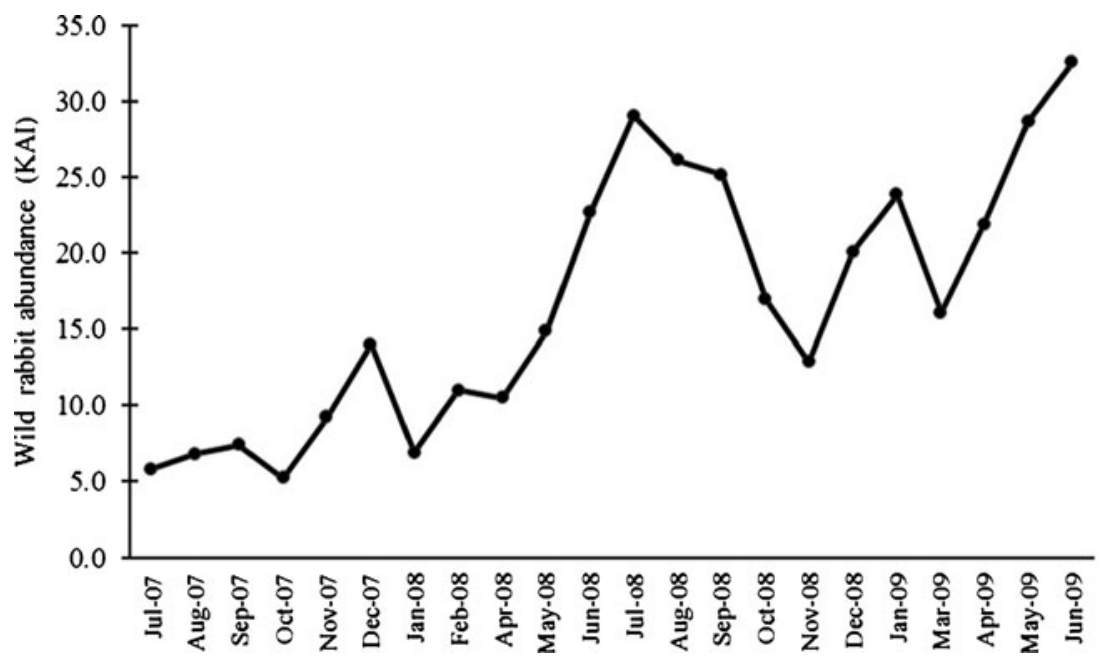

importance on wild rabbit presence and abundance (Fig. 4). Regarding the rabbit presence, we found that the most important variable was the season, with 0.93 of relative importance (Fig. 4). However, WDI, EDI, and PC4-SD were also important predictors for wild rabbit presence, presenting, respectively, $0.78,0.77$, and 0.69 of relative importance (Fig. 4). As for wild rabbit abundance, the WDI and the PC2-LA were the most important predictors with 0.86 of relative importance, followed by the $\mathrm{SE}$ predictor $\left(\sum w_{i}=\right.$ 0.67; Fig. 4). PC1-LA and PC3-LA did not show significant effects on wild rabbit occurrence and abundance (Fig. 4).

\section{Discussion}

In the present study, we evaluated the importance of environmental, habitat management, and season factors on the distribution and abundance of a low-density wild rabbit population. As hypothesized, habitat management techniques seem to play a very important role in the species occurrence and abundance in a small-scale analysis. In fact, in sites where environmental conditions are the limiting factors, in our case, the absence of soft soils for digging warrens, the importance of habitat management techniques (building artificial warrens) is highlighted.
Habitat management techniques

In the present study, we found that the main factors influencing wild rabbit presence and abundance were the season and shelter attributes (WDI and PC2-LA), respectively. Indeed, the positive effect of artificial warrens in restoring wild rabbit population had been documented in a study carried out between 1997 and 2009 in Serra da Malcata, Portugal (Sarmento et al. 2012). It has been found that wild rabbit can live aboveground when a dense scrub layer is present (e.g., Kolb 1994). Also, similar findings have been reported for southwestern Portugal (near our study area; Beja et al. 2007). It is widely known, however, that wild rabbit distribution and abundance is influenced by soil type (Delibes-Mateos et al. 2009), mainly because the species usually depends on warrens for breeding and refuge against predators and climatic extremes (Parer and Libke 1985). Hard soils (Leptosols), where it is very difficult for wild rabbit to dig warrens, covered about $78.1 \%$ of our study area. In such conditions, the underground refuge becomes a limiting factor (Parer and Libke 1985; Trout and Smith 1995; Lombardi et al. 2003; Calvete et al. 2004; Williams et al. 2007). Thus, in the Algarve mountain range, artificial warrens seem to be a main alternative for shelter and nesting sites contributing to increase the habitat carrying capacity.
Fig. 3 Habitat management and annual mean wild rabbit abundance (latrines per kilometer)

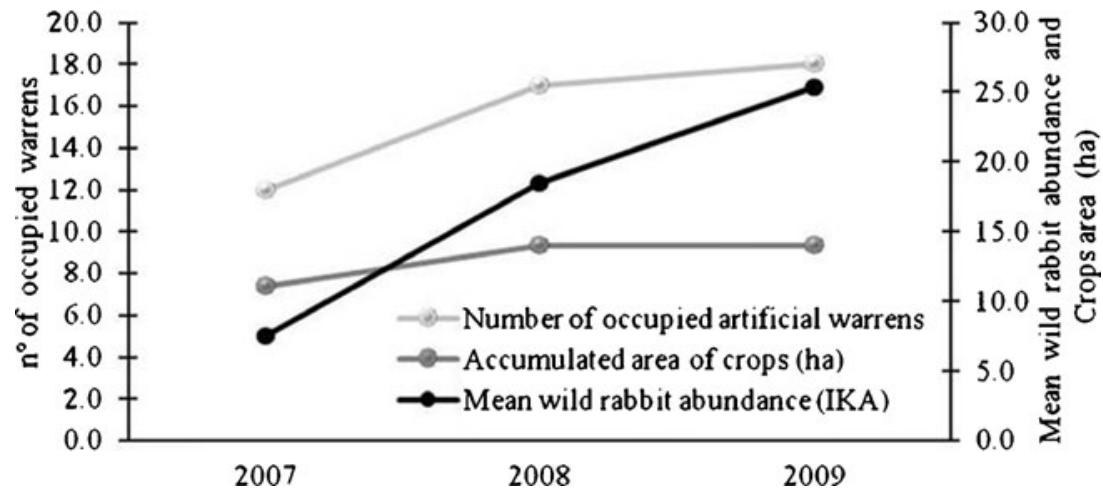


Table 3 Coefficients and their significance of univariate GLMM and LMM models for rabbit presence and abundance data

\begin{tabular}{|c|c|c|c|c|c|c|}
\hline \multirow[t]{2}{*}{ Variables } & \multicolumn{3}{|c|}{ Rabbit presence } & \multicolumn{3}{|c|}{ Rabbit abundance } \\
\hline & $\beta$ & SE & $p$ value & $\beta$ & SE & $p$ value \\
\hline TSD & -0.593 & 0.457 & 0.194 & -0.101 & 0.061 & 0.101 \\
\hline WDI & 1.855 & 0.453 & $0.000 * * *$ & 0.199 & 0.051 & $0.000 * * *$ \\
\hline EDI & 0.976 & 0.307 & $0.001 * *$ & 0.071 & 0.033 & $0.030 *$ \\
\hline PC1-SD & -0.153 & 0.511 & 0.764 & -0.045 & 0.069 & 0.519 \\
\hline PC2-SD & 0.659 & 0.520 & 0.205 & 0.055 & 0.069 & 0.432 \\
\hline PC3-SD & -0.609 & 0.479 & 0.203 & -0.072 & 0.069 & 0.301 \\
\hline PC4-SD & -1.660 & 0.517 & $0.001 * *$ & -0.211 & 0.062 & $0.001 * *$ \\
\hline PC1-LA & 2.304 & 0.773 & $0.002 * *$ & 0.249 & 0.066 & $0.000 * * *$ \\
\hline PC2-LA & -0.271 & 0.263 & 0.303 & -0.088 & 0.031 & $0.006^{* *}$ \\
\hline PC3-LA & 0.525 & 0.305 & $0.085^{\dagger}$ & 0.133 & 0.042 & $0.002 * *$ \\
\hline Season & 0.488 & 0.149 & $0.001 * *$ & 0.060 & 0.016 & $0.000 * * *$ \\
\hline
\end{tabular}

$T S D$ distance index of temporary streams; $W D I$ distances index of artificial warrens; $E D I$ ecotone distance index; $P C 1-S D$ east and south slope directions; $P C 2-S D$ southeast, southwest, and northwest slope direction; $P C 3-S D$ southwest and northwest slope direction; $P C 4-S D$ north and northeast slope direction; PC1-LA Leptosols, dense bushes, and $Q$. suber without bushes; PC2-LA Cambisols and Pinus sp. with bushes; PC3-LA crops

${ }^{*} p<0.05 ; * * p<0.01 ; * * * p<0.001 ;{ }^{\dagger} p<0.1$

Creating pasturelands and open areas in large bush patches to promote ecotone zones seems to have a positive effect on wild rabbit presence. We found, however, that the proportion of crop area in a sample plot had no significant direct effects on wild rabbit presence and abundance. It seems that the abundant spontaneous herbaceous species

Table 4 Set of best candidate models for rabbit presence and abundance variables

\begin{tabular}{|c|c|c|c|c|c|c|}
\hline Model set & Model & Variables contained in the model & AIC & $\mathrm{AICc}$ & $\Delta_{i}$ & $w_{i}$ \\
\hline \multirow[t]{13}{*}{ Rabbit presence } & 1 & $\mathrm{WDI}^{(+)}+\mathrm{EDI}^{(+)}+\mathrm{PC} 4-\mathrm{SD}^{(-)}+\mathrm{SE}^{+}$ & 307.91 & 308.08 & 0.00 & 0.23 \\
\hline & 2 & $\mathrm{WDI}+\mathrm{EDI}+\mathrm{PC} 4-\mathrm{SD}+\mathrm{PC} 1-\mathrm{LA}+\mathrm{SE}$ & 309.03 & 309.27 & 1.19 & 0.13 \\
\hline & 3 & $\mathrm{WDI}+\mathrm{EDI}+\mathrm{SE}$ & 309.23 & 309.34 & 1.26 & 0.12 \\
\hline & 4 & $\mathrm{WDI}+\mathrm{EDI}+\mathrm{PC} 4-\mathrm{SD}+\mathrm{PC} 3-\mathrm{LA}+\mathrm{SE}$ & 309.81 & 310.05 & 1.97 & 0.09 \\
\hline & 5 & $\mathrm{EDI}+\mathrm{PC} 4-\mathrm{SD}+\mathrm{SE}$ & 310.03 & 310.14 & 2.06 & 0.08 \\
\hline & 6 & $\mathrm{WDI}+\mathrm{EDI}+\mathrm{PC} 3-\mathrm{LA}+\mathrm{SE}$ & 311.06 & 311.23 & 3.15 & 0.05 \\
\hline & 7 & $\mathrm{WDI}+\mathrm{PC} 4-\mathrm{SD}+\mathrm{SE}$ & 311.12 & 311.23 & 3.15 & 0.05 \\
\hline & 8 & $\mathrm{WDI}+\mathrm{EDI}+\mathrm{PC} 4-\mathrm{SD}+\mathrm{PC} 1-\mathrm{LA}+\mathrm{PC} 3-\mathrm{LA}+\mathrm{SE}$ & 311.02 & 311.25 & 3.17 & 0.05 \\
\hline & 9 & $\mathrm{WDI}+\mathrm{EDI}+\mathrm{PC} 1-\mathrm{LA}+\mathrm{SE}$ & 311.14 & 311.31 & 3.23 & 0.05 \\
\hline & 10 & $\mathrm{EDI}+\mathrm{PC} 4-\mathrm{SD}+\mathrm{PC} 1-\mathrm{LA}+\mathrm{SE}$ & 311.46 & 311.63 & 3.55 & 0.04 \\
\hline & 11 & $\mathrm{EDI}+\mathrm{PC} 4-\mathrm{SD}+\mathrm{PC} 3-\mathrm{LA}+\mathrm{SE}$ & 311.66 & 311.83 & 3.75 & 0.04 \\
\hline & 12 & $\mathrm{WDI}+\mathrm{SE}$ & 311.87 & 311.94 & 3.86 & 0.03 \\
\hline & Null model & Intercept & 333.42 & 333.43 & 25.35 & 0.00 \\
\hline \multirow[t]{6}{*}{ Rabbit abundance } & 1 & $\mathrm{WDI}^{+}+\mathrm{PC}_{2}-\mathrm{LA}^{+}+\mathrm{SE}^{+}$ & 391.83 & 391.95 & 0.00 & 0.42 \\
\hline & 2 & $\mathrm{WDI}+\mathrm{PC} 2-\mathrm{LA}+\mathrm{PC} 3-\mathrm{LA}+\mathrm{SE}$ & 393.79 & 393.96 & 2.01 & 0.15 \\
\hline & 3 & $\mathrm{WDI}+\mathrm{PC} 1-\mathrm{LA}+\mathrm{PC} 2-\mathrm{LA}$ & 394.57 & 394.69 & 2.74 & 0.11 \\
\hline & 4 & $\mathrm{WDI}+\mathrm{PC} 1-\mathrm{LA}+\mathrm{PC} 2-\mathrm{LA}+\mathrm{SE}$ & 394.61 & 394.78 & 2.83 & 0.10 \\
\hline & 5 & $\mathrm{WDI}+\mathrm{PC} 2-\mathrm{LA}$ & 394.98 & 395.05 & 3.11 & 0.09 \\
\hline & Null model & Intercept & 409.46 & 409.47 & 17.52 & 0.00 \\
\hline
\end{tabular}

$S E$ season; $W D$ distances index of artificial warrens; $E D I$ ecotone distance index; $P C 4-S D$ north and northeast slope direction; $P C 1-L A$ Leptosols, dense bushes, and $Q$. suber without bushes; PC2-LA cambisols and Pinus sp. with bushes; PC3-LA crops

$(+)$ and $(-)$ represent, respectively, the positive and negative relationship between independent and dependent variables selected in the best model. For rabbit presence, we ran 63 possible models and 127 for rabbit abundance. 

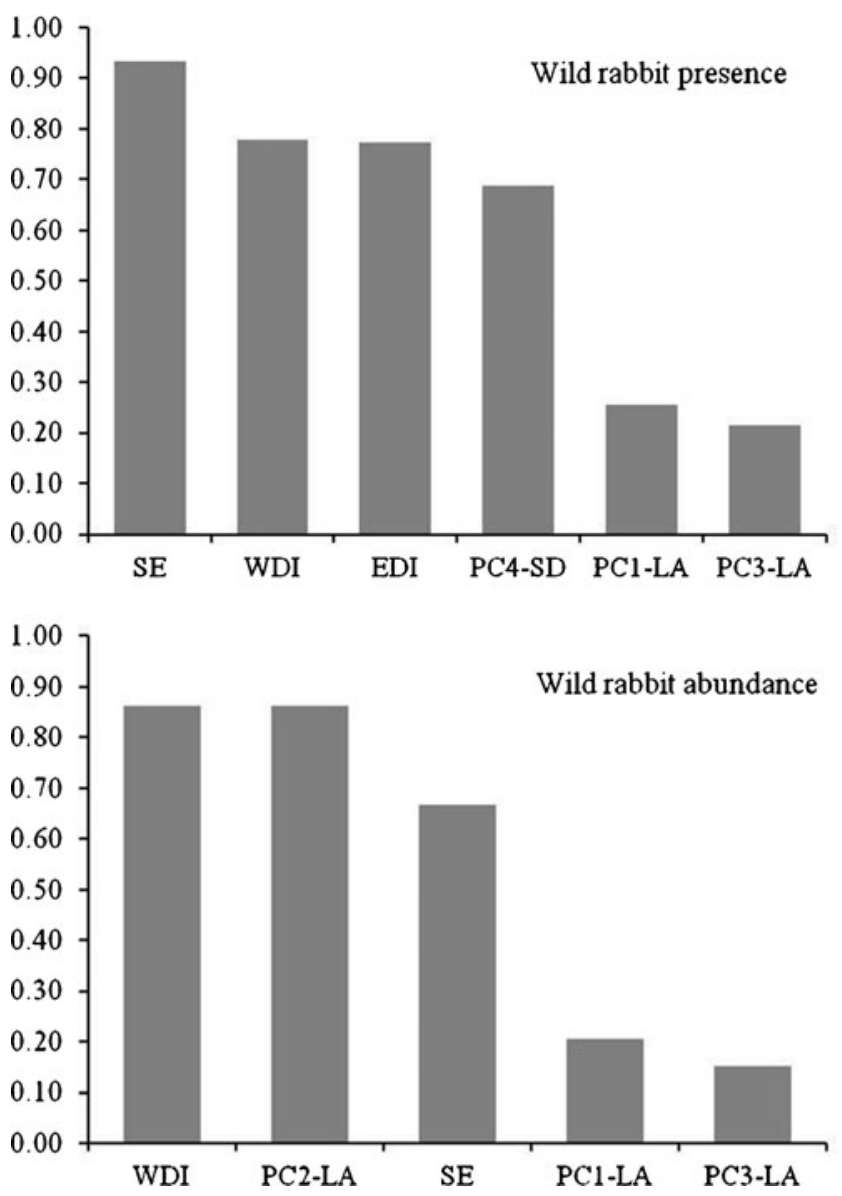

Fig. 4 Variable relative importance. Vertical axis show the range of relative importance values (0-1). SE season; WDI distances index of artificial warrens; $E D I$ ecotone distance index; $P C 4-S D$ north and northeast slope direction; $P C 1-L A$ leptosols, dense bushes, and $Q$. suber without bushes; PC2-LA cambisols and Pinus sp. with bushes; $P C 3-L A$ crops

present in the area, mostly resulting from bush clear cuts, are providing food with a similar quality to crops. In fact, it has been shown in southwest of Portugal that wild rabbit in the presence of spontaneous herbaceous do not positively select crops (Ferreira and Alves 2005), and that bush clear cut can provide herbaceous plants, which are important complementary rabbit food items (Ferreira and Alves 2009).

Our results clearly show that the ecotone distances gradient plays a very important role in the probability of wild rabbit presence. In accordance to other studies (Moreno et al. 1996; Palomares and Delibes 1997; Lombardi et al. 2003, 2007; Fernández 2005), the present results support the idea that wild rabbit presence is highly associated with the ecotone between bushes and crops/open areas. Furthermore, we found that the distance from the ecotone exerts a major influence on wild rabbit presence, which significantly increased in areas less than $100 \mathrm{~m}$ from the ecotone. Commonly, studies have demonstrated that wild rabbit is more abundant at sites where feeding habitats are closer to refuge patches, such as ecotone zones (Rogers and Myers 1979; Rogers 1981; Moreno and Villafuerte 1995; Virgós et al. 2003). Conversely, but in agreement with Calvete et al. (2004), our results did not show a clear effect of ecotone on wild rabbit abundance. It seems that in the absence of soft soils, which allow wild rabbits to dig suitable warrens, the ecotone itself does not assure refuge enough to support high densities. Therefore, wild rabbit increase depends more on artificial warrens than on ecotone existence. In fact, the present study's results showed that the highest rabbit abundance values were recorded in sample plots where artificial warrens were situated in close proximity to both bush and crop/open areas. Although, we may not discard that the lack of relationship between ecotone and rabbit abundance is a consequence of the latrine counts method limitations due to the strong behavioral component of latrines (Monclús and de Miguel 2003).

The distance class that affected wild rabbit the most, namely less than $100 \mathrm{~m}$ from artificial warrens and from the ecotone zone, is consistent with the movement patterns shown by the species in several different environments (Cowan 1991; Gibb 1993; Künkele and von Holst 1996; Villafuerte and Moreno 1997; Richardson et al. 2002; Calvete et al. 2004).

\section{Environmental factors}

We found a negative relationship between wild rabbit presence and north and northeast slopes, which had not been reported previously. We suspect that wild rabbits avoid these slopes because they tend to be wet and cold (less sun exposure), and such environments favor litter mortality (Rödel et al. 2009). In addition, according to GarciaBocanegra et al. (2010), the Spilopsyllus cuniculi flea, which finds its physiological optimal conditions in wet sites (Osácar-Jimenez et al. 2001), is an important disease vector in the European wild rabbit.

Our results show that wild rabbit abundance is highly associated with good shelter (soft soils, artificial warrens, and bushes), where wild rabbit can breed and find refuge with low predation risk. In fact, opportunistic predators can prevent the recovery of the wild rabbit populations, not allowing them to reach carrying capacity, especially when density is low (Newsome et al. 1989; Delibes-Mateos et al. 2009).

\section{Seasonal factors}

As expected, we noticed remarkable seasonal changes in wild rabbit distribution and abundance over the 22-month period study. Regarding abundance, a consistent seasonal pattern was found across all monitoring periods, with a significant rabbit increase (latrines per kilometer) from early spring to the midsummer and a marked decrease in late autumn when effects of the dry season cease. With the first rains at the beginning of winter, pasture improvement in 
quantity and quality stimulates wild rabbit reproduction (Gonçalves et al. 2002). In summary, the seasonal patterns we observed agree with other research carried out in Portugal (Ferreira and Alves 2009) and Spain (Beltrán 1991; Villafuerte et al. 1997).

Notably, the season effect was more important in predicting wild rabbit distribution than wild rabbit abundance. Plant phenology may partially explain the strong seasonal variations on rabbit distribution. In fact, wild rabbit strategies of using space depend on the availability of different plant species and on their actual nutritive value (Soriguer 1988; Rueda et al. 2008; Ferreira and Alves 2009). And, wild rabbit reproductive phenology, which is clearly influenced by plant phenology (Gonçalves et al. 2002; Martins et al. 2002), also seems to play an important role on seasonal changes in distribution. In fact, natal dispersal, that is, offspring moving away from their original nucleus to a vacant nearby area, is a markedly seasonal phenomenon with an obvious impact in terms of distribution.

\section{Conclusions and management implications}

Wild rabbit is a keystone prey species and is therefore a fundamental element in the conservation programs of many endangered carnivores in the Mediterranean ecosystems of the Iberian Peninsula (Delibes-Mateos et al. 2007). In Portugal and Spain, wild rabbits are also of great importance as game species, with their hunting revenues being an important income for many rural estates (Virgós et al. 2007; Paixão et al. 2009). Thus, wild rabbit population recovery may serve both conservation and socioeconomic purposes. In southern Portugal, a captive breeding program of the Iberian lynx started in 2009 with the aim of preparing (reproductive and genetically) appropriate individuals for future restocking in its historic territories. This restocking operation will be made in close cooperation with the LIFE IBERLINCE project, which main objectives are to promote suitable habitat and prey density for reintroducing Iberian lynx. Given the particular importance of the Caldeirão mountain range for Iberian lynx (historical species territories), the present study provides useful information regarding how environmental variables, management techniques, and season affect wild rabbit probability presence and levels of abundance. This knowledge can be used as a valuable tool in wild rabbit recovery projects mainly in other similar important areas for Iberian lynx, such as the AlgarveOdemira region (southwest Portugal) and Western Sierra Morena-Guadiana (southwest Portugal and southeast Spain; see Sarmento et al. 2009).

As we have shown, the main limiting factor of wild rabbit occurrence and level of abundance in this Mediterranean landscape was refuge availability, where the proximity to artificial warrens seems to be a positive influence on wild rabbit presence and abundance. Good management practices, and therefore, an ideal combination of bushes, crop patches, and distances to artificial warrens are crucial for improving wild rabbit habitat and, as the present study's results suggest, for increasing wild rabbit probability of presence and abundance. Given our initial wild rabbit population (two small wild rabbit nuclei), the management techniques implemented surrounding these nuclei and the success verified, we propose four habitat management recommendations in the context of similar areas (e.g., with soils limitation) for promoting wild rabbit presence and abundance increasing: (1) scrublands management actions should promote a landscape matrix where the shrub layer is discontinued by crops or open areas; (2) artificial warrens should be built near bushes and crops/open areas ecotones because feeding areas close to refuge/breeding shelters are limiting factors; (3) the distance from any point in the managed area to an artificial warren and to an ecotone should be less than $100 \mathrm{~m}$ and ideally less than $50 \mathrm{~m}$; and (4) habitat management should be addressed to slopes with more sun exposure because cold-wet areas might be unfavorable to wild rabbits. These measures will provide better access to key habitat elements and promote wild rabbits' habitat-carrying capacity.

Acknowledgements This research was supported by the Electric National Grid (REN). We would like to thank the hunters from the Associação de Caçadores de Querença for their valuable assistance with fieldwork.

The authors are also thankful to EGSP - Energia e Sistemas de Potência, Lda.

\section{Appendix I}

Instead of focusing in each recorded latrine or rabbit nuclei identified, we defined our sampling unit as a square plot with $250 \times 250 \mathrm{~m}$, where we collected and computed all the information about the studied variables (dependent and independent).

Temporary streams, ecotone and artificial warrens were considered as important habitat elements. We aimed at assessing the availability of these habitat elements, within each sample plot, considering both their proximity and quantity. For that, we defined distance classes and measured the area occupied by each one of them (see Figure for ecotone distance e.g.) using the Spatial Analyst extension with a 'Find distance' function of ArcView 3.2 software.

We used this approach instead of simpler distances measures (e.g., the distance from the sample plot centroid to the nearest artificial warren, the mean distance from the sample plot centroid to all artificial warrens, etc.) because we 
believe that distance classes proportion and distribution in each sample plot is a better resource availability descriptor.

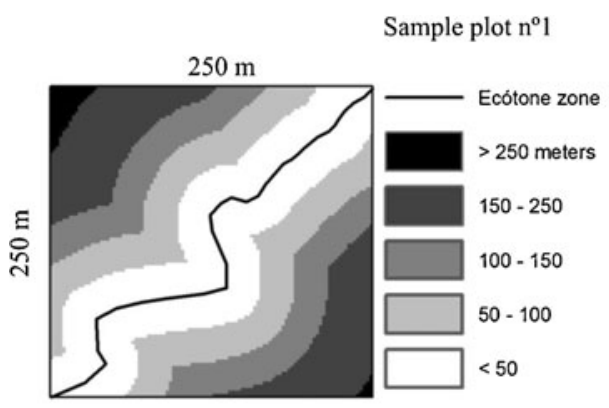

Propotion area 0.05 0.30

0.10

0.15

0.40

Figure - Ecotone distance gradient

Slope direction calculation

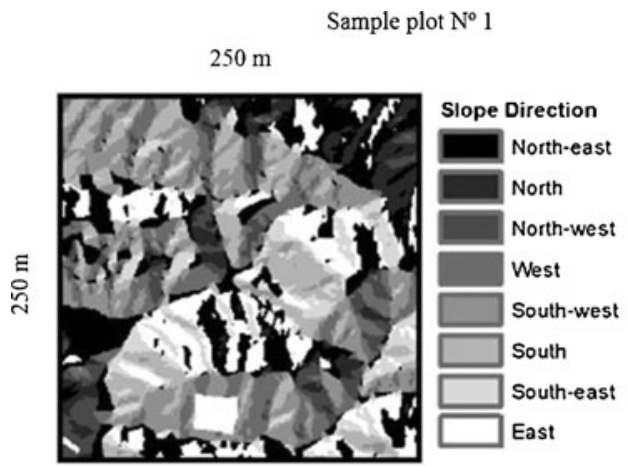

Proportion area

0.25

0.10

0.05

0.02

0.05

0.30

0.08

0.15

\section{References}

Angulo E, Villafuerte R (2003) Modelling hunting strategies for the conservation of wild rabbit populations. Biol Cons 115:291-301

Barrio IC, Bueno CG, Tortosa FS (2009) Improving predictions of the location and use of warrens in sensitive rabbit populations. Anim Conserv 12:426-433

Barrio IC, Villafuerte R, Tortosa FS (2011) Harbouring pests: rabbit warrens in agricultural landscapes. Wild Res 38:756-761

Bates D, Maechler M (2010) lme4: Linear mixed-effects models using S4 classes. R package. Available at: http://www.R-project.org. Accessed 10 Sept 2011

Beja P, Pais M, Palma L (2007) Rabbit Oryctolagus cuniculus habitats in mediterranean scrubland: the role of scrub structure and composition. Wildl Biol 13:28-37

Beja P, Gordinho L, Reino L, Loureiro F, Santos-Reis M, Borralho R (2008) Predator abundance in relation to small game management in Southern Portugal: conservation implications. Wild Res $55: 227-238$

Beltrán JF (1991) Temporal abundance pattern of the wild rabbit in Doñana, SW Spain. Mammalia 55(4):591-599

Bjornstad ON (2009) ncf: spatial nonparametric covariance functions. R package. Available at: http://www.R-project.org. Accessed 10 September 2011

Burnham KP, Anderson DR (2002) Model selection and multimodel inference: a practical information-theoretic approach. Springer, New York, p 488
Calvete C, Villafuerte R, Lucientes J, Osacar JJ (1997) Effectiveness of traditional wild rabbit restocking in Spain. J Zool (Lond) 241:271-277

Calvete C, Estrada R, Angulo E, Cabezas-Ruiz S (2004) Habitat factors related to wild rabbit conservation in an agricultural landscape. Landsc Ecol 19:531-542

Calvete C, Pelayo E, Sampietro J (2006) Habitat factors related to wild rabbit population trends after the initial impact of rabbit haemorrhagic disease. Wild Res 33:467-474

Catalán I, Rodríguez-Hidalgo P, Tortosa FS (2008) Is habitat management an effective tool for wild rabbit (Oryctolagus cuniculus) population reinforcement? Eur J Wildl Res 54:449-453

Cowan DP (1991) The availability of burrows in relation to dispersal in the wild rabbit Oryctolagus cuniculus. Symp Zool Soc Lond 63:213-230

Delibes M, Hiraldo F (1981) The rabbit as prey in the Iberian mediterranean ecossystem. In: Myers $\mathrm{K}$, McInnes $\mathrm{CD}$ (eds) Proceedings of the World Lagomorph Conference. University of Guelph, Ontario

Delibes-Mateos M, Redpath S, Angulo E, Ferreras P, Villafuerte R (2007) Rabbits as a keystone species in southern Europe. Biol Cons 137:149-156

Delibes-Mateos M, Delibes M, Ferreras P, Villafuerte R (2008a) The key role of European rabbits in the conservation of the western Mediterranean basin hotspot. Cons Biol 22(5):1106-1117

Delibes-Mateos M, Ferreras P, Villafuerte R (2008b) Rabbit populations and game management: the situation after 15 years of rabbit haemorrhagic disease in central-southern Spain. Biodiv Cons 17:559-574

Delibes-Mateos M, Ramírez E, Ferreras P, Villafuerte R (2008c) Translocations as a risk for the conservation of European wild rabbit Oryctolagus cuniculus lineages. Oryx 42(2):259-264

Delibes-Mateos M, Ferreras P, Villafuerte R (2009) European rabbit population trends and associated factors: a review of the situation in the Iberian Peninsula. Mamm Rev 39:124-140

Delibes-Mateos M, Farfán MÁ, Olivero J, Vargas JM (2010) Land-use changes as a critial factor for long-term wild rabbit conservation in the Iberian Peninsula. Environ Conserv 37:1-8

Fernández N (2005) Spatial patterns in European rabbit abundance after a population collapse. Landsc Ecol 20:897-910

Fernández-Olalla M, Martínez-Jauregui M, Guil F, San Miguel-Ayanz A (2010) Provision of artificial warens as a means to enhance native wild rabbit populations: what type of warren and where should they be sited? Eur J Wildl Res 56:829-837

Fernandez-de-Simon J, Díaz-Ruiz F, Cirilli F, Tortosa FS, Villafuerte R, Delibes-Mateos M, Ferreras P (2011) Towards a standardized index of European rabbit abundance in Iberian Mediterranean habitats. Eur J Wildl Res 57:1091-1100

Ferreira C, Alves PC (2005) Impacto da implementação de medidas de gestão do habitat nas populações de coelho-bravo (Oryctolagus cuniculus algirus) no Parque Natural do Sudoeste Alentejano e Costa Vicentina. Final Report of the CIBIO-UP/ICN collaboration protocol

Ferreira C, Alves PC (2009) Influence of habitat management on the abundance and diet of wild rabbit (Oryctolagus cuniculus algirus) populations in Mediterranean ecosystems. Eur J Wildl Res 55:487-496

Ferreira C (2012) European rabbit research in the Iberian Peninsula: state of the art and future perspectives. Eur J Wildl Res 58:885895

García-Bocanegra I, Astorga RJ, Napp S, Casal J, Huerta B, Borge C, Arenas A (2010) Myxomatosis in wild rabbit: design of control programs in Mediterranean ecosystems. Prev Vet Med 93:4250

Gibb JA (1993) Sociality, time and space in a sparse population of rabbits (Oryctolagus cuniculus). J Zool (Lond) 229:581-607 
Gonçalves H, Alves PC, Rocha A (2002) Seasonal variation in the reproductive activity of the wild rabbit (Oryctolagus cuniculus) in a Mediterranean ecosystem. Wild Res 29:165-173

Iborra O, Lumaret JP (1997) Validity limits of the pellet group counts in wild rabbit (Oryctolagus cuniculus). Mammalia 61:205-218

Kolb HH (1994) The use of cover and burrows by a population of rabbits (Mammalia: Oryctolagus cuniculus) in eastern Scotland. Journal of Zoology 233:9-17

Künkele J, von Holst D (1996) Natal dispersal in the European wild rabbit. Anim Behav 51:1047-1059

Legendre P, Legendre L (1998) Numerical ecology. Elsevier, Amsterdam, p 853

Lombardi L, Fernández N, Moreno S, Villafuerte R (2003) Habitatrelated differences in rabbit (Oryctolagus cuniculus) abundance, distribution and activity. J Mamm 84(1):26-36

Lombardi L, Fernández N, Moreno S (2007) Habitat use and spatial behaviour in the European rabbit in three Mediterranean environments. Basic Appl Ecol 8:453-463

Martins H, Milne JA, Rego F (2002) Seasonal and spatial variation in the diet of the wild rabbit (Oryctolagus cuniculus L.) in Portugal. J Zool (Lond) 258:395-404

Monclús R, de Miguel FJ (2003) Distribuición espacial de las letrinas de conejo (Oryctolagus cuniculus) en el monte de Valdelatas (Madrid). Galemys 15:157-165

Monteiro F (1994) Estudo de um repovoamento de Coelho-bravo (Oryctolagus cuniculus) no Parque Nacional de Doñana: Factores condicionantes do seu resultado. Degree final report. Sciences Faculty. University of Porto, Portugal

Moreno S, Villafuerte R (1995) Traditional management of scrubland for the conservation of rabbits Oryctolagus cuniculus and their predators in Doñana National Park, Spain. Biol Cons 73:81-85

Moreno S, Villafuerte R, Delibes M (1996) Cover is safe during the day but dangerous at night: the use of vegetation by European wild rabbits. Can J Zool 74:1656-1660

Moreno S, Villafuerte R, Cabezas S, Lombardi L (2004) Wild rabbit restocking for predator conservation in Spain. Biol Cons 118:183-193

Newsome AE, Parer I, Catling PC (1989) Prolonged prey suppression by carnivores - predator-removal experiments. Oecologia 78:458 467

Osácar-Jimenez JJ, Lucientes-Curdi J, Calvete-Margolles C (2001) Abiotic factors influencing the ecology of wild rabbits fleas in north-eastern Spain. Med Vet Entomol 15:157-166

Paixão R, Godinho S, Santos P (2009) Is the Nature 2000 Network associated with small-game bag results? Eur J Wildl Res 55:553-559

Palomares F, Calzada J, Revilla E (1996) El manejo del hábitat y la abundancia de conejos: diferencias entre dos áreas potencialmente idénticas. Rev Florest 9(1):201-210

Palomares F, Delibes M (1997) Predation upon European rabbits and their use of open and closed patches in Mediterranean habitats. Oikos 80:407-411

Palomares F (2003) Warren building by European rabbits (Oryctolagus cuniculus) in relation to cover availability in a sandy area. J Zool (Lond) 259:63-67

Parer I, Libke JA (1985) Distribution of rabbit, Oryctolagus cuniculus, warrens in relation to soil types. Aust Wildl Res 12:387-405

Pinheiro J, Bates DM, DebRoy S, Sarkar D (2007) nlme: Linear and nonlinear mixed effects models. R package. Available at: http:// www.R-project.org. Accessed 10 Sept 2011
Richardson BJ, Hayes RA, Wheeler SH, Yardin MR (2002) Social structures, genetic structures and dispersal strategies in Australian rabbit (Oryctolagus cuniculus) populations. Behav Ecol Sociobiol $51: 113-121$

Rivas-Martínez S, Lloidi J (1999) Biogeography of the Iberian Peninsula. Itinera Geobot 13:49-67

Rogers PM, Myers K (1979) Ecology of the European Wild Rabbit, Oryctolagus cuniculus (L.), in Mediterranean Habitats. I. Distribution in the landscape of the Coto Doñana, S. Spain. Appl Ecol 16:691-703

Rogers PM (1981) Ecology of the European Wild Rabbit, Oryctolagus cuniculus (L.), in Mediterranean Habitats. II. Distribution in the landscape of the Camargue, S. France. Appl Ecol 18:355-371

Rueda M, Rebollo S, Bravo LG (2008) Age and season determine European rabbit habitat use in Mediterranean ecosystems. Acta Oecol 34:266-273

Rödel HG, Starkloff A, Seltmann MW, Prager G, von Holst D (2009) Causes and predictors of nest mortality in a European rabbit population. Mamm Biol 74:198-209

Sarmento P, Cruz J, Monterroso P, Tarroso P, Ferreira C, Negrões N, Eira C (2009) Status survey of critically endangered Iberian lynx Lynx pardinus in Portugal. Eur J Wildl Res 55:247-253

Sarmento P, Cruz J, Paula A, Eira C, Capinha M, Ambrósio I, Ferreira C, Fonseca C (2012) Occupancy, colonization, and extinction patterns of rabbit populations: implications for Iberian lynx conservation. Eur J Wildl Res 58:523-533

Soriguer RC (1988) Alimentación del conejo (Oryctolagus cuniculus L.1758) en Doñana. SO, España. Acta Vert 15:141-150

SROA (Serviço de Reconhecimento e Ordenamento Agrário) (1961) Carta de Solos de Portugal no 5-C. Ministério da Economia, Secretaria de Estado da Agricultura, Lisbon

Trout RC, Smith GC (1995) The reproductive productivity of the wild rabbit (Oryctolagus cuniculus) in Southern England on sites with different soils. J Zool (Lond) 237:411-422

Villafuerte R, Calvete C, Blanco JC, Lucientes J (1995) Incidence of viral hemorrhagic disease in wild rabbit populations in Spain. Mammalia 59:651-659

Villafuerte R, Lazo A, Moreno S (1997) Influence of food abundance and quality on rabbit fluctuations: conservation and management implications in Doñana National Park (SW Spain). Rev Ecol $52: 345-356$

Villafuerte R, Moreno S (1997) Predation risk, cover type, and group size in European rabbits in Doñana (SW Spain). Acta Ther 42:225-230

Virgós E, Cabezas-Díaz S, Malo A, Lozano J, López-Huertas D (2003) Factors shaping European rabbit abundance in continuous and fragmented populations of central Spain. Acta Ther 48:113-122

Virgós E, Cabezas-Díaz S, Lozano J (2007) Is the wild rabbit (Oryctolagus cuniculus) a threatened species in Spain? Sociological constraints in the conservation of species. Biodiv Cons 16:3489-3504

Williams D, Acevedo P, Gortázar C, Escudero MA, Labarta JL, Marco J, Villafuerte R (2007) Hunting for answers: rabbit (Oryctolagus cuniculus) population trends in northeastern Spain. Eur J Wildl Res 53:19-28

Zuur AF, Ieno EN, Walker NJ, Saveliev AA, Smith GM (2009) Mixed effects models and extensions in ecology with R. Springer, New York, p 574 